\title{
Novel management of a necrotic pancreatic fluid collection with staged cystgastrostomy followed by cystgastrojejunostomy: the Lizzie Grace maneuver
}

A 58-year-old man with severe alcoholrelated necrotizing pancreatitis was admitted and was treated initially with conservative management including aggressive intravenous fluid hydration and placement of a percutaneous gastrojejunostomy tube for enteral nutrition. Endoscopic retrograde cholangiopancreatography (ERCP) was performed with no evidence of pancreatic duct disruption or contrast leakage, but sludge was swept from the bile duct and biliary sphincterotomy was performed. Endoscopic ultrasound (EUS) revealed acute inflammatory changes in the entire pancreas without any well-formed fluid collection that could be drained.

The patient was treated conservatively with aggressive intravenous fluid hydration, bowel rest, and enteral nutrition for 4 weeks. He subsequently developed sepsis and a repeat computed tomography (CT) scan was performed, which demonstrated a large, complex $17 \times 7-\mathrm{cm}$ pancreatic fluid collection that was extending from the left anterior perirenal space to the left lower quadrant in the pelvis.

EUS-guided cystgastrostomy was performed with a 15-mm lumen-apposing metal stent (LAMS; Axios, Boston Scientific, Natick, Massachusetts, USA). An ultrathin upper gastrointestinal (GI) endoscope was then used to enter the cyst cavity and a necrotic fistula tract was identified that extended into the jejunum with necrosis involving the jejunal lumen. Wire guidance was used to place a bridging esophageal fully covered self-expanding metal stent (FCSEMS; Wallstent, Boston Scientific) across the jejunal fistula tract with the distal end being in the jejunum and the proximal end in the stomach via the LAMS creating a cystgastrojejunostomy ( Video 1). A 12-mm over-thescope clip (OTSC; Ovesco, Cary, North Carolina, USA) was used to anchor the FCSEMS to the gastric mucosa to prevent migration.
A repeat CT scan 2 weeks later showed interval improvement in the necrotic fluid collection but a $13 \times 2.7-\mathrm{cm}$ residual collection was seen extending deep into the left pelvis ( $\triangleright$ Fig. $\mathbf{1}$ ). The decision was made to pursue repeat EUS-guided drainage through the existing cystgastrostomy fistula to access the deep pelvic collection.
An upper Gl endoscopy was performed with removal of the bridging cystgastrojejunostomy stents. The fistula tract appeared mature. An echoendoscope was then advanced through the fistula tract into the jejunum. The posterior pancreatic fluid collection was identified; a 15-mm LAMS (Axios, Boston Scientific) was deployed using an EUS-guided tech-

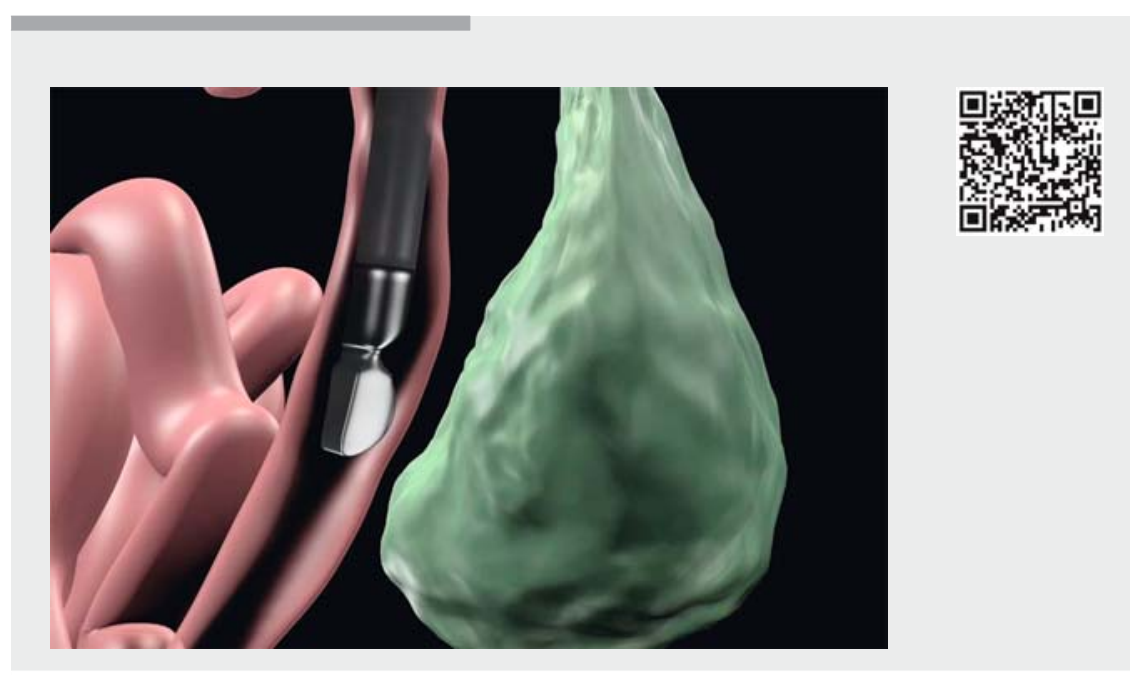

Video 1 The use of a gastrojejunostomy to perform drainage of a pelvic collection.

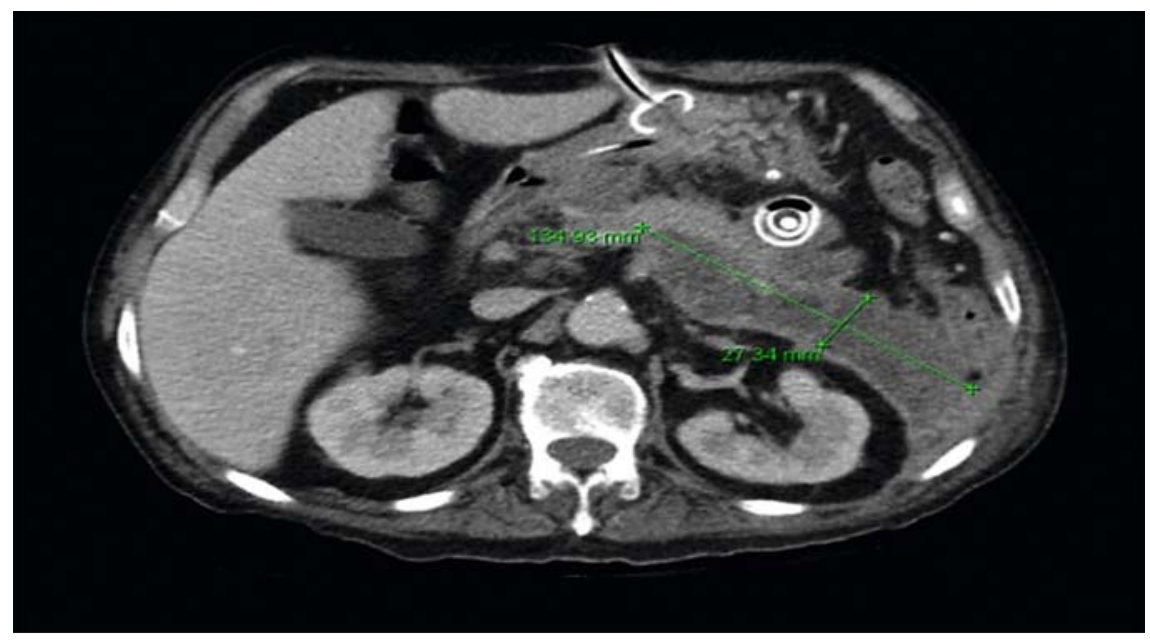

- Fig. 1 Computed tomography (CT) scan showing the pelvic fluid collection facing the esophageal stent placed through the gastrojejunostomy. 
nique with the distal end in the necrotic cavity and the proximal end in the jejunum, resulting in the drainage of pus and fluid ( Video 1 ). The patient underwent multiple necrosectomies through the cystgastrojejunostomy with complete resolution of the pancreatic necrosis at his final follow-up 9 months later.

The most common locations for pancreatic fluid collections are close to the stomach or the first part of the small bowel where EUS-guided drainage via cystgastrostomy or cystenterostomy can be readily performed [1-3]. In our patient, the walled-off necrosis was located in the pelvis, making access to the collection more difficult. The use of this novel technique allows deep and difficult-toreach pelvic pancreatic fluid collections to be drained using a bridging technique with combined placement of LAMSs [4] and FCSEMSs across long fistula tracts, as we have demonstrated here.

Endoscopy_UCTN_Code_TTT_1AR_2AI

Competing interests

Michel Kahaleh has received grant support from Boston Scientific, Fujinon, EMcison, Xlumena Inc., W.L. Gore, MaunaKea, Apollo Endosurgery, Cook Endoscopy, ASPIRE Bariatrics, GI Dynamics, NinePoint Medical, Merit Medical, Olympus and MI Tech. He is a con- sultant for Boston Scientific, Xlumena Inc., Concordia Laboratories Inc, ABBvie, and MaunaKea Tech. Nikhil Kumta is a consultant for Boston Scientific.

The Authors

Ming-ming Xu, Nikhil Kumta, Pawan

Marfatia, Viviana Parra, Gustavo Silva, Elizabeth Grace Brown, Amy Tyberg, Reem Sharaiha, Michel Kahaleh

Division of Gastroenterology, Weill Cornell

Medical, New York, New York, USA

\section{Corresponding author}

\section{Michel Kahaleh, MD}

Division of Gastroenterology and

Hepatology, Weill Cornell Medical, New York, New York, USA

Fax: +1-646-962-0110

mkahaleh@gmail.com

\section{References}

[1] Shah RJ, Shah JN, Waxman I et al. Safety and efficacy of endoscopic ultrasound-guided drainage of pancreatic fluid collections with lumen-apposing covered self-expanding metal stents. Clin Gastroenterol Hepatol 2015; 13: $747-752$

[2] Tyberg A, Karia K, Gabr M et al. Management of pancreatic fluid collections: A comprehensive review of the literature. World $]$ Gastroenterol 2016; 22: 2256-2270
[3] Binmoeller KF, Shah J. A novel lumen-apposing stent for transluminal drainage of nonadherent extraintestinal fluid collections. Endoscopy 2011; 43: 337 - 342

[4] Siddiqui AA, Kowalski TE, Loren DE et al. Fully covered self-expanding metal stents versus lumen-apposing fully covered self-expanding metal stent versus plastic stents for endoscopic drainage of pancreatic walled-off necrosis: clinical outcomes and success. Gastrointest Endosc 2017; 85: 758 - 765

\section{Bibliography}

DOI https://doi.org/10.1055/s-0043-117999

Published online: 13.9.2017

Endoscopy 2017; 49: E290-E291

(c) Georg Thieme Verlag KG

Stuttgart · New York

ISSN 0013-726X

\section{ENDOSCOPY E-VIDEOS}

https:/|eref.thieme.de/e-videos

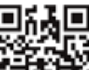

Endoscopy E-Videos is a free access online section, reporting on interesting cases and new

techniques in gastroenterological endoscopy. All papers include a high quality video and all contributions are freely accessible online.

This section has its own submission website at

https://mc.manuscriptcentral.com/e-videos 